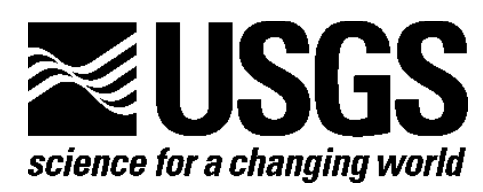

\title{
Magnetotelluric Data Collected to Characterize Aquifers in the San Luis Basin, New Mexico
}

\author{
By Chad E. Ailes and Brian D. Rodriguez
}

Open-File Report 2014-1248 


\section{U.S. Department of the Interior \\ SALLY JEWELL, Secretary}

\section{U.S. Geological Survey \\ Suzette M. Kimball, Acting Director}

U.S. Geological Survey, Reston, Virginia: 2015

For more information on the USGS-the Federal source for science about the Earth, its natural and living resources, natural hazards, and the environment-visit http://www.usgs.gov or call 1-888-ASK-USGS

For an overview of USGS information products, including maps, imagery, and publications, visit $h$ ttp://www.usgs.gov/pubprod

To order this and other USGS information products, visit $h$ ttp://store.usgs.gov

Suggested citation:

Ailes, C.E., and Rodriguez, B.D., 2015, Magnetotelluric data collected to characterize aquifers in the San Luis Basin, New Mexico: U.S. Geological Survey Open-File Report 2014-1248, 9 p., http://dx.doi.org/10.3133/ofr20141248.

Any use of trade, firm, or product names is for descriptive purposes only and does not imply endorsement by the U.S. Government.

Although this information product, for the most part, is in the public domain, it also may contain copyrighted materials as noted in the text. Permission to reproduce copyrighted items must be secured from the copyright owner.

ISSN 2331-1258 (online) 


\section{Contents}

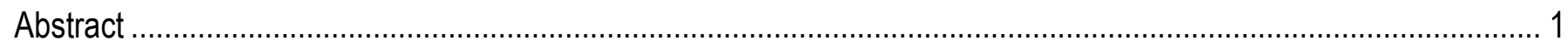

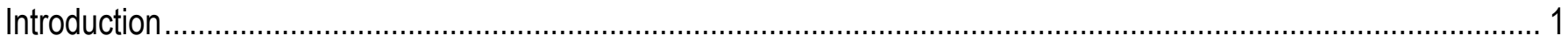

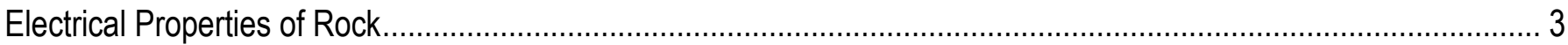

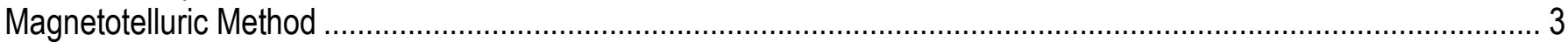

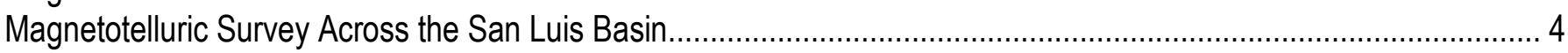

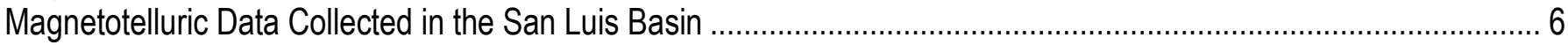

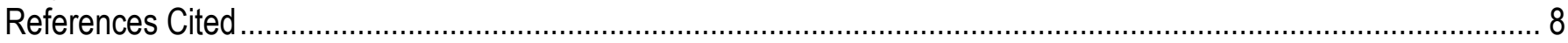

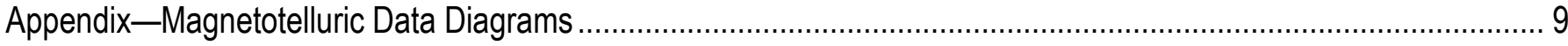

\section{Figure}

1. Magnetotelluric stations (profiles A, B, and C) across the San Luis Basin, northern New Mexico

\section{Tables}

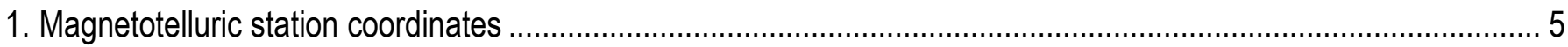

2. Stacked auto and cross power spectra estimates.................................................................................. link 


\section{Conversion Factors}

Inch/Pound to SI

\begin{tabular}{|c|c|c|}
\hline Multiply & By & To obtain \\
\hline \multicolumn{3}{|c|}{ Length } \\
\hline foot $(\mathrm{ft})$ & 0.3048 & meter $(\mathrm{m})$ \\
\hline mile (mi) & 1.609 & kilometer (km) \\
\hline yard (yd) & 0.9144 & meter $(\mathrm{m})$ \\
\hline \multicolumn{3}{|l|}{$\underline{\text { SI to Inch/Pound }}$} \\
\hline Multiply & By & To obtain \\
\hline \multicolumn{3}{|c|}{ Length } \\
\hline meter (m) & 3.281 & foot $(\mathrm{ft})$ \\
\hline kilometer $(\mathrm{km})$ & 0.6214 & mile (mi) \\
\hline meter $(\mathrm{m})$ & 1.094 & yard (yd) \\
\hline
\end{tabular}

Vertical coordinate information is referenced to the 1866 Clarke Spheroid.

Horizontal coordinate information is referenced to the North American Datum of 1927 (NAD 27).

Elevation, as used in this report, refers to distance above the vertical datum. 


\title{
Magnetotelluric Data Collected to Characterize Aquifers in the San Luis Basin, New Mexico
}

\author{
By Chad E. Ailes and Brian D. Rodriguez
}

\begin{abstract}
The U.S. Geological Survey is conducting a series of multidisciplinary studies of the San Luis Basin as part of the Geologic Framework of Rio Grande Basins project. Detailed geologic mapping, high-resolution airborne magnetic surveys, gravity surveys, magnetotelluric surveys, and hydrologic and lithologic data are being used to better understand the aquifers in the San Luis Basin. This report describes one north-south and two east-west regional magnetotelluric sounding profiles, acquired in June of 2010 and July and August of 2011, across the San Luis Basin in northern New Mexico. No interpretation of the data is included.
\end{abstract}

\section{Introduction}

The population of the San Luis Basin region of northern New Mexico is growing. Future growth and land management decisions in this low rainfall region where rainfall is 19 to $32 \mathrm{~cm} /$ year (Bartolino and Cole, 2002) depend on an accurate assessment and protection of the groundwater resources. The Santa Fe Group aquifer system in the San Luis Basin is the main source of municipal water for the region (Bartolino and Cole, 2002). An important aspect of managing the groundwater resources is a better understanding of the hydrogeology of the Santa Fe Group aquifer system and the nature of other sedimentary deposits that fill the Rio Grande Rift.

The U.S. Geological Survey is conducting a series of multidisciplinary studies of the San Luis Basin as part of the Geologic Framework of Rio Grande Basins project. Detailed geologic mapping, high-resolution airborne magnetic surveys, gravity surveys, magnetotelluric surveys, and hydrologic and lithologic data are being used to better understand the aquifers in the San Luis Basin. Ailes and Rodriguez (2010) describe the first magnetotelluric surveys collected in 2009. This report describes regional magnetotelluric-sounding profiles acquired in June of 2010 and July and August of 2011 across the San Luis Basin where drillhole data are sparse (fig. 1). Resistivity modeling of the magnetotelluric data can be used to help map changes in electrical resistivity with depths that are related to differences in rock types. These various rock types influence the fluid-flow properties of the aquifers. The purpose of this report is to release the magnetotelluric sounding data collected along the profiles. No interpretation of the data is included. 


\section{Magnetotelluric profiles across the Taos Plateau volcanic field}
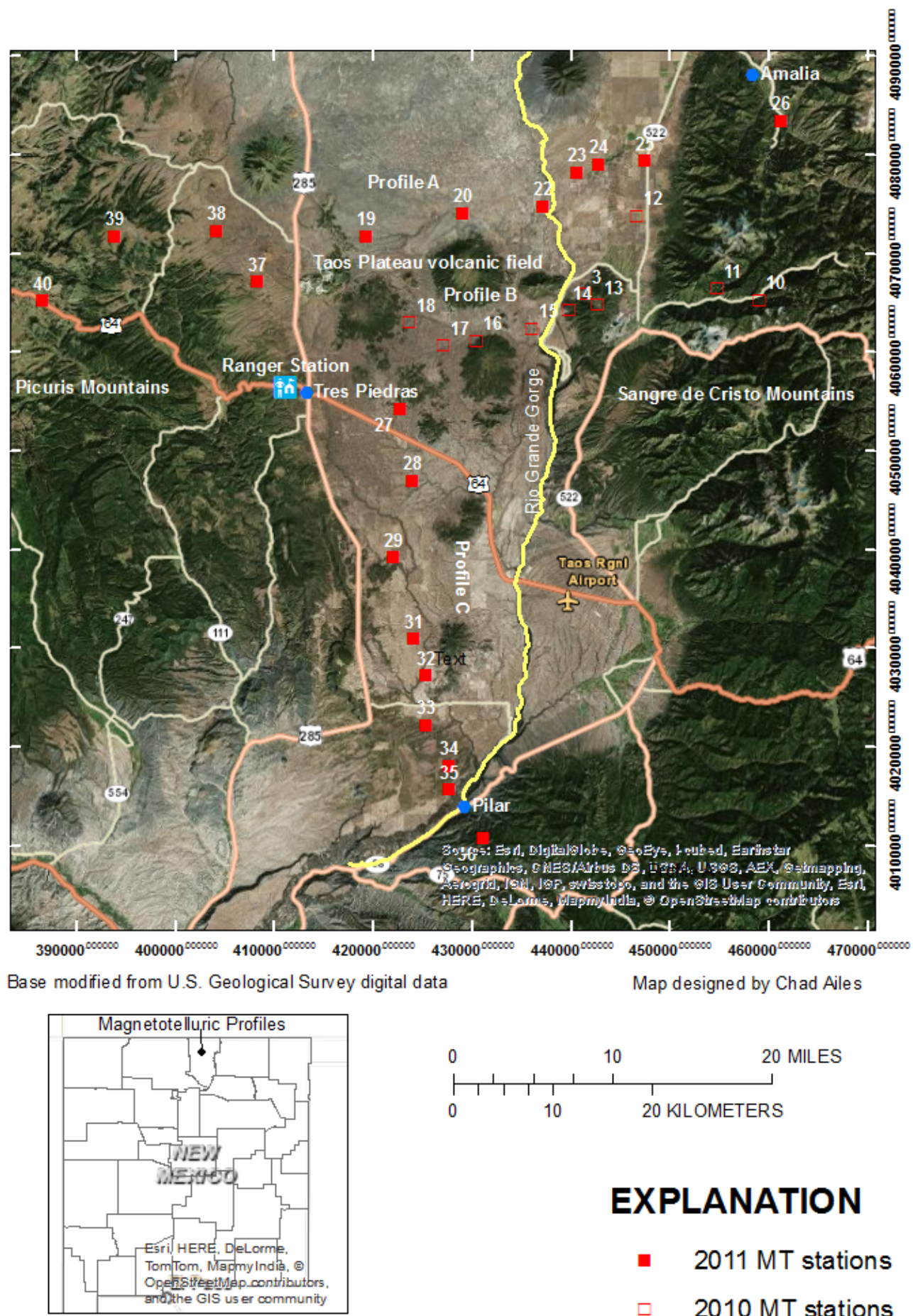

\section{EXPLANATION}

- 2011 MT stations

$2010 \mathrm{MT}$ stations

Figure 1. Magnetotelluric stations (profiles A, B, and C) across the San Luis Basin, northern New Mexico. 


\section{Electrical Properties of Rock}

Electromagnetic geophysical investigation methods detect variations in the electrical properties of rock units, in particular electrical resistivity measured in units of ohm-meters (ohm-m), or its inverse, electrical conductivity measured in units of Siemens/meter $(\mathrm{S} / \mathrm{m})$. Electrical resistivity can be correlated with geologic units on the surface and at depth using lithologic logs to provide a three-dimensional (3D) picture of subsurface geology. In the upper crust, the resistivities of geologic units are largely dependent upon their fluid content, pore volume porosity, interconnected fracture porosity, and conductive mineral content (Keller, 1987).

Although there is not a one-to-one relationship between lithology and resistivity, there are general correlations that can be made using typical values, even though values can be found at other geographic locations (Palacky, 1987) that may fall outside of the ranges presented below. Fluids within the pore spaces and fracture openings, especially if saline, can reduce resistivities in what would otherwise be a resistive rock matrix (Keller and Frischknecht, 1966; Hearst and Nelson, 1985; Keller, 1987; Palacky, 1987; Hallenburg, 1998; Hearst and others, 2000). Resistivity can also be lowered by the presence of electrically conductive clay minerals, graphitic carbon, and metallic mineralization. It is common, for example, for altered volcanic rocks to contain replacement minerals that have resistivities 10 times lower than those of the surrounding rocks (Nelson and Anderson, 1992). Fine-grained sediments - such as clay-rich alluvium, marine shales, and other mudstones - are normally conductive, with resistivities ranging from a few ohm-m to tens of ohm-m (Keller, 1987; Palacky, 1987).

Metamorphic rocks (nongraphitic) and unaltered, unfractured igneous rocks are normally moderately to highly resistive (a few hundred to thousands of ohm-m). Carbonate rocks can have similarly high resistivities depending on their fluid content, porosity, and impurities (Keller, 1987; Palacky, 1987). Fault zones may be moderately conductive (tens of ohm-m) when composed of rocks fractured enough to have hosted fluid transport and consequent mineralogical alteration (Eberhart-Phillips and others, 1995). At greater depths, higher subsurface temperatures cause higher ionic mobility that reduces rock resistivities (Keller, 1987; Palacky, 1987). Tables of electrical resistivity for a variety of rocks, minerals, and geological environments may be found in Keller (1989) and Palacky (1987).

\section{Magnetotelluric Method}

The magnetotelluric method is a passive-surface geophysical technique that uses the Earth's natural electromagnetic fields to investigate the electrical resistivity structure of the subsurface from depths of tens of meters to tens of kilometers (Vozoff, 1991). Natural variations of the Earth's magnetic and electric fields are measured and recorded at each magnetotelluric station. Worldwide lightning activity at frequencies of about 1 to 20,000 Hertz and geomagnetic micropulsations at frequencies of about 1 to 0.0001 Hertz provide the majority of the signal sensed by the magnetotelluric method. The natural electromagnetic waves propagate vertically in the Earth because the large contrast between the resistivity of the air and the Earth causes a vertical refraction of the electromagnetic wave at the surface (Vozoff, 1972).

The orthogonal horizontal electric (Ex, Ey), magnetic (Hx, Hy), and vertical magnetic (Hz) field components are recorded in the magnetotelluric method. The resulting time-series signals are used to derive tensor-apparent resistivities and phases after first converting them to complex cross-spectra using fast Fourier transform (FFT) techniques and least-squares, cross-spectral analysis (Bendat and Piersol, 1971) to solve for a tensor transfer function. If one assumes that the Earth consists of a two-input, twooutput linear system in which the orthogonal magnetic fields are input and the orthogonal electric fields are output, then a transfer function can be calculated that relates the observed electric fields to the 
magnetic fields. For resistivity modeling, data are normally rotated in directions that are parallel and perpendicular to the subsurface geologic strike. Subsurface geologic strike can be estimated by determining the horizontal direction (Hx or Hy) that the vertical magnetic field (Hz) "tips" (the Tipper strike direction).

For a two-dimensional (2D) model, the magnetotelluric fields can be decoupled into transverse electric and transverse magnetic modes. Two-dimensional resistivity modeling generally is computed to fit both modes. When the geology satisfies the two-dimensional assumption, the magnetotelluric data for the transverse electric mode are assumed to represent the electric field oriented along geologic strike, and the data for the transverse magnetic mode are assumed to represent the electric field oriented across strike. The magnetotelluric method is well suited for studying complicated geological environments because the electric and magnetic relations are sensitive to vertical and horizontal variations in resistivity. High-resolution shallow subsurface characterization is possible for closely spaced stations, but the resolution of the subsurface decreases for deeper measurements and for widely spaced stations. The method is capable of establishing whether the electromagnetic fields are responding to subsurface rock bodies of effectively one, two, or three dimensions. An introduction to the magnetotelluric method and references for a more advanced understanding can be found in Kaufman and Keller (1981), Dobrin and Savit (1988), and Vozoff (1991).

\section{Magnetotelluric Survey Across the San Luis Basin}

Thirty magnetotelluric soundings were collected in northern New Mexico during June of 2010 (stations 3, 10-18) and July and August of 2011 (stations 19-40). The soundings form three profiles that include a 77-kilometer ( $\mathrm{km}$ )-long east-west profile (fig. 1, Profile A), a 35-km-long east-west profile (fig. 1, Profile B), and a 44-km-long north-south profile (fig. 1, Profile C). Profile A starts at station 40 in the Tusas Mountains just north of State Highway 64. From station 40, profile A continues easterly across the Taos Plateau volcanic field and the Rio Grande Gorge. Profile A ends at station 26, in the Sangre de Cristo Mountains, about $12 \mathrm{~km}$ east of State Highway 522 and about $5 \mathrm{~km}$ south of the town of Amalia, New Mexico. Profile B starts at station 18 on the Taos Plateau Volcanic Field about $12 \mathrm{~km}$ east of State Highway 285. From station 18 profile B continues easterly across the Rio Grande Gorge. Profile B ends at station 10, in the Sangre de Cristo Mountains, about $12 \mathrm{~km}$ east of State Highway 522 and the town of Questa, New Mexico. Profile C starts at station 27 on the Taos Plateau Volcanic Field about $9 \mathrm{~km}$ east of State Highway 285 and the Tres Piedras Ranger Station. From station 27, profile C continues southerly across the Rio Grande Gorge. Profile C ends at station 36 in the Picuris Mountains about $4 \mathrm{~km}$ south of State Highway 522 and the town of Pilar, New Mexico. These profile locations were selected to map electrical resistivity with depth to characterize fluid-flow properties of aquifers in the San Luis Basin, northern New Mexico.

Station locations were chosen for proximity to roads and to avoid electrical noise from power lines. All data at the stations were collected with a portable Electromagnetic Instruments, Inc. (EMI) MT24LF system (EMI, Inc., 2002). Horizontal electric fields were measured using copper-sulfate porous pot electrodes placed in an L-shaped, three-electrode array with dipole lengths of $30 \mathrm{~m}$. The orthogonal horizontal magnetic fields in the direction of the electric-field measurement array were measured using high-magnetic-permeability, mu-metal-cored induction coils (EMI, Inc., 1996). Frequencies were sampled from about 0.002 to 200 Hertz using remote-referenced recordings of the orthogonal, horizontal components of the electric and magnetic fields and the vertical magnetic field. Table 1 lists the 30 magnetotelluric station locations included in this report. 
Table 1. Magnetotelluric station coordinates.

[Remote is remote-reference station. Coordinates are referenced to the 1866 Clarke Spheroid and North American Datum of 1927 (NAD 27) Western United States datum. Longitude and latitude format is degrees:minutes:seconds. Universal Transverse Mercator (UTM Zone 13) units and station elevations are in meters (m). The accuracy of the north and east component is \pm 5 meters and is \pm 10 meters for the elevation. $\mathrm{X}$ direction (X Dir) is in degrees clockwise from true north.]

\begin{tabular}{rrrrrrrr}
\hline Station & Remote & Longitude & Latitude & Easting $(\mathbf{m})$ & Northing $(\boldsymbol{m})$ & Elevation & X Dir \\
\hline & & & & & & & \\
\hline 40 & 39 & $-106: 16: 15$ & $36: 43: 4$ & 386523 & 4065257 & 3073 & 41 \\
\hline 39 & 40 & $-106: 11: 22$ & $36: 47: 1$ & 393875 & 4071745 & 2927 & 183 \\
\hline 38 & 37 & $-106: 04: 28$ & $36: 47: 3$ & 404128 & 4072339 & 2694 & 175 \\
\hline 37 & 38 & $-106: 01: 36$ & $36: 44: 5$ & 408351 & 4067126 & 2606 & 172 \\
\hline 19 & 27 & $-105: 54: 17$ & $36: 47: 2$ & 419273 & 4071730 & 2442 & 262 \\
\hline 20 & 22 & $-105: 47: 43$ & $36: 48: 4$ & 429074 & 4074092 & 2332 & 205 \\
\hline 22 & 20 & $-105: 42: 17$ & $36: 49: 0$ & 437147 & 4074795 & 2294 & 331 \\
\hline 23 & 24 & $-105: 39: 58$ & $36: 51: 0$ & 440615 & 4078260 & 2277 & 88 \\
\hline 24 & 23 & $-105: 38: 26$ & $36: 51: 2$ & 442888 & 4079021 & 2278 & 77 \\
\hline 25 & 24 & $-105: 35: 21$ & $36: 51: 3$ & 447483 & 4079370 & 2311 & 79 \\
\hline 26 & none & $-105: 26: 07$ & $36: 53: 5$ & 461223 & 4083445 & 2573 & 282 \\
\hline 18 & 16 & $-105: 51: 12$ & $36: 42: 4$ & 423776 & 4063033 & 2355 & 152 \\
\hline 17 & 15 & $-105: 48: 52$ & $36: 41: 2$ & 427228 & 4060670 & 2320 & 7 \\
\hline 16 & 18 & $-105: 46: 43$ & $36: 41: 4$ & 430441 & 4061162 & 2364 & 109 \\
\hline 15 & 17 & $-105: 42: 55$ & $36: 42: 2$ & 436100 & 4062427 & 2306 & 93 \\
\hline 14 & 13 & $-105: 40: 26$ & $36: 43: 2$ & 439828 & 4064227 & 2334 & 190 \\
\hline 3 & 12 & $-105: 39: 18$ & $36: 44: 2$ & 441531 & 4065912 & 2335 & 279 \\
\hline 13 & 14 & $-105: 38: 28$ & $36: 43: 4$ & 442760 & 4064832 & 2423 & 270 \\
\hline 12 & 3 & $-105: 35: 50$ & $36: 48: 3$ & 446716 & 4073792 & 2335 & 188 \\
\hline 11 & 10 & $-105: 30: 19$ & $36: 44: 4$ & 454889 & 4066495 & 2727 & 325 \\
\hline 10 & 11 & $-105: 27: 30$ & $36: 44: 0$ & 459081 & 4065283 & 2791 & 205 \\
\hline 27 & 19 & $-105: 51: 49$ & $36: 37: 5$ & 422793 & 4054188 & 2373 & 156 \\
\hline 28 & 29 & $-105: 51: 00$ & $36: 34: 0$ & 423931 & 4046999 & 2294 & 139 \\
\hline 29 & 31 & $-105: 52: 10$ & $36: 29: 4$ & 422135 & 4039229 & 2301 & 148 \\
\hline 31 & 29 & $-105: 50: 46$ & $36: 25: 2$ & 424136 & 4030949 & 2217 & 180 \\
\hline 32 & none & $-105: 49: 57$ & $36: 23: 2$ & 425348 & 4027242 & 2176 & 275 \\
\hline 33 & 35 & $-105: 49: 54$ & $36: 20: 3$ & 425372 & 4022251 & 2123 & 20 \\
\hline 34 & 36 & $-105: 48: 18$ & $36: 18: 2$ & 427720 & 4018081 & 2103 & 65 \\
\hline 35 & 33 & $-105: 48: 20$ & $36: 17: 0$ & 427652 & 4015718 & 2100 & 61 \\
\hline 36 & 34 & $-105: 45: 56$ & $36: 14: 2$ & 431198 & 4010725 & 2380 & 292 \\
\hline & & & & & & & \\
\hline & & & & & & \\
\hline & & & & & & & \\
\hline
\end{tabular}




\section{Magnetotelluric Data Collected in the San Luis Basin}

The recorded time-series data were converted to the frequency domain and processed to determine the impedance tensor, which is used to derive apparent resistivities and phases at each site. Rotation of the impedance tensor allows for decoupling into the transverse electric and transverse magnetic modes. The data provided here have not been rotated from the original acquisition orientation (X Dir) listed in table 1. During the analysis and interpretation process, each station should be rotated to a fixed angle determined by the given nominal profile orientation. Cross-power files were sorted to select optimal signal-to-noise time-series datasets (see appendix and table 2).

Table 2. Stacked auto and cross-power spectra estimates. [Link to MS Excel file.]

Cultural features, such as fences, pipelines, communication lines, moving vehicles and trains, and other man-made sources of electromagnetic noise, can contaminate the magnetotelluric signals. Care was taken to avoid these noise sources during data acquisition.

The figures in the appendix represent the processed magnetotelluric data for each station, after the time-series data were converted to the frequency domain and the tensor-transfer function was applied.

Data for each station are presented in eight diagrams.

1. Apparent Resistivity for the unrotated xy (x symbol) and yx (o symbol) modes,

2. Impedance Phase for the unrotated xy (x symbol) and yx (o symbol) modes,

3. Impedance Skew for the impedance tensor,

4. Multiple Coherency for the xy (x symbol) and minimum (o symbol) modes of the electric field,

5. Impedance Polar Diagrams (at 12 selected frequencies),

6. Tipper Magnitude for the vertical magnetic field,

7. Tipper Strike for the vertical magnetic field, and

8. HzHx (x symbol) and HzHy (o symbol) Coherency.

Units of measure for apparent resistivity, phase, and tipper strike are given in the diagrams. The coherency diagrams, the skew, the tipper magnitude, and the polar diagrams have unitless vertical axes. The data for all diagrams are shown over a range of frequencies. Error bars (],[) on the Apparent Resistivity, Impedance Phase, Impedance Skew, Tipper Magnitude, and Tipper Strike diagrams represent probable errors within one standard deviation of the sample variance (Gamble and others, 1979).

Apparent resistivity is calculated from the ratio of the electric field strength magnitude over the magnetic field strength magnitude for a given frequency. The impedance phase is proportional to the slope of the apparent resistivity curve on a log-log diagram, relative to a baseline at $-45^{\circ}$ (Vozoff, 1991). A measure of the dimensionality for magnetotelluric data is provided by the impedance skew of the impedance tensor (Vozoff, 1972). If the effective, measured resistivity response to the geology beneath a magnetotelluric station is truly one- or two-dimensional, then the skew will be zero. Both instrumental and environmental sources of noise contribute to nonzero skew values but are typically small (about 0.1) for relatively low-noise-level recordings. Higher skews (more than 0.2) indicate either the resistivity response to 3D geology or higher levels of noise. 
In the study area, noise from a number of small powerlines and small moving vehicles was negligible beyond $0.25 \mathrm{~km}$ from the noise source. Power-line signal amplitude levels were measured at each site and were typically less than 20 percent of the maximum recordable signals. Noise from larger power lines, power generators, pipelines, and trains was negligible at distances greater than $5 \mathrm{~km}$. Local lightning can also degrade data quality, but signals recorded during active thunderstorms were not used in the data processing. Burying the magnetic induction coils and keeping the electric dipole wires flat on the ground helped to minimize wind noise.

Predicted values of the electric field can be computed from the measured values of the magnetic field (Vozoff, 1991). The coherence of the predicted electric field with the measured electric field is a measure of the signal-to-noise ratio provided in the multiple coherency diagrams. Values are normalized between 0 and 1 , where values at 0.5 signify signal levels equal to noise levels. For this data set, coherencies were generally above 0.75 , except in the middle frequencies (from about 0.1 Hertz to 5 Hertz) at most stations.

The figures in the appendix represent the processed magnetotelluric data at each station and they include some data scatter and poor signal-to-noise ratios. The only effort aimed at removing noisy data points was to visually inspect and digitally select the best signal-to-noise field data to combine into the final data diagrams.

The impedance polar diagrams provide a measure of the magnetotelluric data dimensionality (Reddy and others, 1977). For one-dimensional (1D) resistivity structures, the principal impedance (offdiagonal elements) polar diagram (dashed line) is a circle. For 2D or 3D resistivity structures, the principal impedance polar diagram (dashed line) elongates either parallel to or perpendicular to strike direction. Over resistors, the principal impedance polar diagram elongates perpendicular to strike direction; while over conductors, the principal impedance polar diagram elongates parallel to strike direction. For 2D resistivity structures, the additional impedance polar diagram (solid line) attains the shape of a symmetric clover leaf. For 3D resistivity structures, the additional impedance polar diagram (solid line) elongates in one direction, and its amplitude is comparable to that of the principal impedance polar diagram (dashed line); although, high noise levels can produce the same effect on the polar diagram. A 3D analysis of polar diagrams at each frequency should also take into account the corresponding coherence and skew values along with their associated error levels. The polar diagrams computed for our data show the electromagnetic response for all stations was predominantly 3D over all frequencies measured at acceptable noise levels, except for stations 18 and 27 that showed a 2D electromagnetic response at the lower frequencies.

The tipper can be calculated from the vertical component of the magnetic field. The tipper magnitude is a measure of the tipping of the magnetic field out of the horizontal plane (Vozoff, 1991). The magnitude is zero for the 1D case, typically increases between 0.1 and 0.5 , and rarely is as great as 1.0 as it responds to vertical and subvertical structures. The tipper strike typically is used to help resolve the $90^{\circ}$ ambiguity in the impedance rotation angle. The tipper magnitude of these stations was all above 0.1 indicating vertical and sub-vertical structure at depth.

The HzHx and HzHy coherency is a measure of the signal-to-noise ratio of the vertical magnetic field with respect to each of the orthogonal, horizontal magnetic field directions. Values are normalized between 0 and 1 , where values of 0.5 signify signal levels equal to noise levels. These three components of magnetic-field coherence provide a check on the quality of the measured values in the tipper magnitude and tipper strike diagrams. 


\section{References Cited}

Ailes, C.E., and Rodriguez, B.D., 2010, Magnetotelluric data, Taos Plateau Volcanic Field, New Mexico: U.S. Geological Survey Open-File Report 2010-1245, 65 p.

Bartolino, J.R., and Cole, J.C., 2002, Ground-water resources of the Middle Rio Grande Basin, New Mexico: U.S. Geological Survey Circular 1222, 132 p.

Bendat, J.S., and Piersol, A.G., 1971, Random data-Analysis and measurement procedures: New York, N.Y., Wiley Interscience, 407 p.

Dobrin, M.D., and Savit, C.H., 1988, Introduction to geophysical prospecting (4th ed.): New York, McGraw-Hill, 867 p.

Eberhart-Phillips, Donna, Stanley, W.D., Rodriguez, B.D., and Lutter, W.J., 1995, Surface seismic and electrical methods to detect fluids related to faulting: Journal of Geophysical Research, v. 100, no. B7, p. 12919-12936.

EMI, Inc., 1996, MT-1 magnetotelluric system operation manual, version 3.2: Richmond, Calif., Electromagnetic Instruments, Inc., 220 p.

EMI, Inc., 2002, MT24/LF system operation and maintenance manual, version 1.0: Richmond, Calif., Electromagnetic Instruments, Inc., 72 p.

Gamble, T.D., Goubau, W.M., and Clarke, J., 1979, Error analysis for remote reference magnetotellurics: Geophysics, v. 44, no. 5, p. 959-968.

Hallenburg, J.K., 1998, Non-hydrocarbon methods of geophysical formation evaluation: Boca Raton, Fla., Lewis Publications, 265 p.

Hearst, J.R., and Nelson, P.H., 1985, Well logging for physical properties: New York, McGraw-Hill Book Co., $571 \mathrm{p}$.

Hearst, J.R., Nelson, P.H., and Paillet, F.L., 2000, Well logging for physical properties, 2nd edition: New York, John Wiley \& Sons, 483 p.

Kaufman, A.A., and Keller, G.V., 1981, The magnetotelluric sounding method, Methods in geochemistry and geophysics, 15: New York, Elsevier, 595 p.

Keller, G.V., 1987, Rock and mineral properties, in Nabighian, M.N., ed., Electromagnetic methods in applied geophysics theory: Tulsa, Okla., Society of Exploration Geophysicists, v. 1, p. 13-51.

Keller, G.V., 1989, Electrical properties, in Carmichael, R.S., ed., Practical handbook of physical properties of rocks and minerals: Boca Raton, Fla., CRC Press, p. 359-427.

Keller, G.V., and Frischknecht, F.C., 1966, Electrical methods in geophysical prospecting: Oxford, Pergamon Press Inc., 519 p.

Nelson, P.H., and Anderson, L.A., 1992, Physical properties of ash flow tuff from Yucca Mountain, Nevada: Journal of Geophysical Research, v. 97, no. B5, p. 823-841.

Palacky, G.J., 1987, Resistivity characteristics of geologic targets, in Nabighian, M.N., ed., Electromagnetic methods in applied geophysics: Tulsa, Okla., Society of Exploration Geophysicists, v. 1, p. 53-129.

Reddy, I.K., Rankin, David, and Phillips, R.J., 1977, Three-dimensional modelling in magnetotelluric and magnetic variational sounding: Geophysics Journal of the Royal Astronomical Society, v. 51, p. 313-325.

Vozoff, Keeva, 1972, The magnetotelluric method in the exploration of sedimentary basins: Geophysics, v. 37, p. 980-141.

Vozoff, Keeva, 1991, The magnetotelluric method, in Nabighian, M.N., ed., Electromagnetic methods in applied geophysics: Tulsa, Okla., Society of Exploration Geophysicists, v. 2, pt. B, p. 641-711. 


\section{Appendix-Magnetotelluric Data Diagrams}

Data for each station are represented by eight diagrams. Units of measure for apparent resistivity, phase, and tipper strike are given in the diagrams. The coherency diagrams, the skew, the tipper magnitude, and the polar diagrams have unitless vertical axes. The data for all diagrams are shown over a range of frequencies.

1. Apparent Resistivity for the unrotated xy (x symbol) and yx (o symbol) modes,

2. Impedance Phase for the unrotated xy (x symbol) and yx (o symbol) modes,

3. Impedance Skew for the impedance tensor,

4. Multiple Coherency for the xy (x symbol) and minimum (o symbol) modes of the electric field,

5. Impedance Polar Diagrams (at 12 selected frequencies),

6. Tipper Magnitude for the vertical magnetic field,

7. Tipper Strike for the vertical magnetic field, and

8. HzHx (x symbol) and HzHy (o symbol) Coherency.

All diagrams erroneously show "Acquired: 19:5 Mar 08, 1998." These diagrams are generated by propriety commercial software that erroneously reads the acquisition date in the data file and defaults the acquisition date to "Mar 08, 1998." Refer to the section "Magnetotelluric Survey Across the San Luis Basin" for the correct dates. Refer to the "Magnetotelluric Data Collected in the San Luis Basin" section in this report for an explanation of these diagrams. 